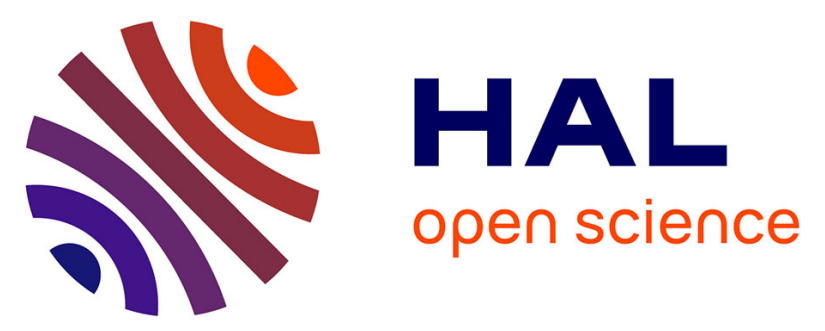

\title{
Development and Evaluation of a Disposable Solid-State Culture Packed-Bed Bioreactor for the Production of Conidia from Trichoderma asperellum Grown Under Water Stress
}

Ynoussa Maïga, Quentin Carboué, Rayhane Hamrouni, Marie-Stéphane

Tranier, Yassine Ben Menadi, Sevastianos Roussos

\section{To cite this version:}

Ynoussa Maïga, Quentin Carboué, Rayhane Hamrouni, Marie-Stéphane Tranier, Yassine Ben Menadi, et al.. Development and Evaluation of a Disposable Solid-State Culture Packed-Bed Bioreactor for the Production of Conidia from Trichoderma asperellum Grown Under Water Stress. Waste and Biomass Valorization, 2021, 12, pp.3223-3231. 10.1007/s12649-020-01210-2 . hal-03142611

\author{
HAL Id: hal-03142611 \\ https://hal.science/hal-03142611
}

Submitted on 29 Mar 2021

HAL is a multi-disciplinary open access archive for the deposit and dissemination of scientific research documents, whether they are published or not. The documents may come from teaching and research institutions in France or abroad, or from public or private research centers.
L'archive ouverte pluridisciplinaire HAL, est destinée au dépôt et à la diffusion de documents scientifiques de niveau recherche, publiés ou non, émanant des établissements d'enseignement et de recherche français ou étrangers, des laboratoires publics ou privés. 
Development and Evaluation of a Disposable Solid-State Culture Packed-Bed Bioreactor for the Production of Conidia from Trichoderma asperellum Grown Under Water Stress Ynoussa Maïga, Quentin Carboué, Rayhane Hamrouni, Marie-Stéphane Tranier, Yassine Ben Menadi \& Sevastianos Roussos

Waste and Biomass Valorization

ISSN 1877-2641 
Your article is protected by copyright and all rights are held exclusively by Springer Nature B.V.. This e-offprint is for personal use only and shall not be self-archived in electronic repositories. If you wish to self-archive your article, please use the accepted manuscript version for posting on your own website. You may further deposit the accepted manuscript version in any repository, provided it is only made publicly available $\mathbf{1 2}$ months after official publication or later and provided acknowledgement is given to the original source of publication and a link is inserted to the published article on Springer's website. The link must be accompanied by the following text: "The final publication is available at link.springer.com". 


\title{
Development and Evaluation of a Disposable Solid-State Culture Packed-Bed Bioreactor for the Production of Conidia from Trichoderma asperellum Grown Under Water Stress
}

\author{
Ynoussa Maïga ${ }^{1,2}$ (D) Q Quentin Carboué ${ }^{1} \cdot$ Rayhane Hamrouni $^{1,3} \cdot$ Marie-Stéphane Tranier $^{1} \cdot$ Yassine Ben Menadi $^{1,4}$. \\ Sevastianos Roussos ${ }^{1}$
}

Received: 7 April 2020 / Accepted: 13 August 2020

(c) Springer Nature B.V. 2020

\begin{abstract}
A new prototype of a disposable solid-state culture bioreactor (DSSCB) belonging to the packed-bed category is developed for the production of fungal conidia. The bioreactor has the advantages of being autoclavable, lightweight and disposable. With a working volume of $39.52 \mathrm{~L}$, it can be used for large-scale production of fungal conidia. The DSSCB was successfully tested under forced aeration for the production of conidia $\left(2.1 \times 10^{10} / \mathrm{g}\right.$ dry substrate in $\left.140 \mathrm{~h}\right)$ from Trichoderma asperellum, a biocontrol fungus. A mixture of sugarcane bagasse, wheat bran, olive pomace, potato flakes and vine shoots was used as substrate. The DSSCB allowed an overall production of $1.26 \times 10^{14}$ conidia. Based on its configuration, the fermented substrate can be easily transported and used in either solid or liquid form, for biocontrol application. This is a significant advance in the field of biomass production in solid-state culture as problems associated with the decontamination of the bioreactor prior to its reuse can be avoided. The study demonstrated that the DSSCB is suitable for the production of conidia using T. asperellum.
\end{abstract}

\section{Graphic Abstract}

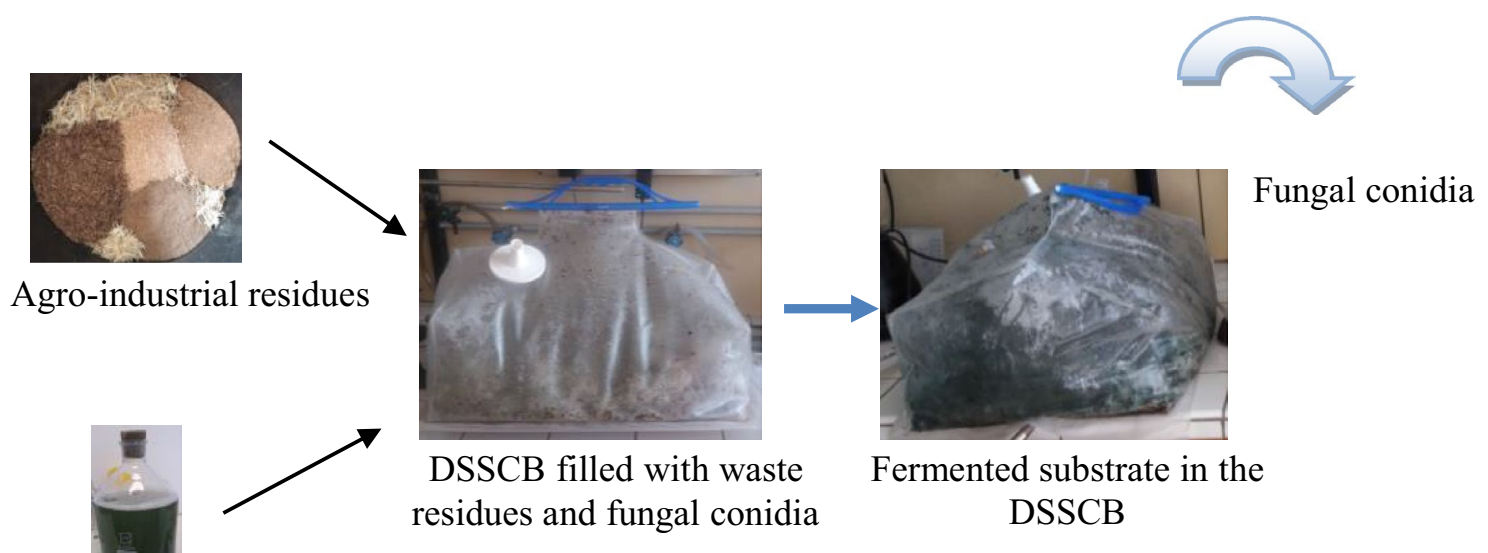

Conidia of Trichoderma asperellum

Keywords Conidia $\cdot$ Solid-state culture $\cdot$ Trichoderma asperellum - Water stress

Ynoussa Maïga

ynoussa.maiga@gmail.com

Extended author information available on the last page of the article 


\section{Statement of Novelty}

Many bioreactors have been developed for the production of bio-active products; however, they are limited by their small size or by difficulties linked to their operation and maintenance. This study reports the development of a disposable solid-state culture bioreactor (DSSCB) with a working volume of $39.52 \mathrm{~L}$, allowing the easy transport of fermented products which can be used in either solid or liquid form, for application in remote farmlands. The DSSCB successfully and massively produced conidia of Trichoderma asperellum, an important biocontrol agent. This is the first report of conidia production in solid-state culture using a disposable bioreactor working at this scale (18 $\mathrm{kg}$ of wet medium).

\section{Introduction}

Solid-state culture (SSC) is generally defined as the culture of microorganisms on a solid medium in the absence (or near absence) of free water, but with enough moisture to support the growth and metabolism of the microorganisms $[1,2]$. When it uses agro-industrial residues as substrates for the production of bio-active products of commercial interest, this process can be classified as a waste management technology [3]. This technology is receiving renewed attention because of the growing need for new metabolites in various industries, such as agriculture, health, food and cosmetics [4]. One of the driving forces in the area of agriculture is that, at the global level, there is an increased desire to reduce the use of chemical pesticides. For example in France, the Ecophyto II + plan aims to reduce the use of chemical pesticides in agriculture by $50 \%$ by 2025 , while offering new alternatives to farmers [5]. As another example, in West Africa, a study conducted in Burkina Faso on pollution by pesticides showed that $30 \%$ of the wells in agricultural zones contain water unsuitable for consumption and $36 \%$ of the vegetables grown have pesticide levels above sanitary standards [6].

Filamentous fungi are good candidates for biocontrol since they can protect crops against phytopathogens and reduce the use of chemical pesticides. Trichoderma strains are very popular, mainly because of their ability to act as highly efficient biofertilizers and biopesticides. They are grown using SSC, for which their metabolism is well adapted. Several studies have investigated the influence of environmental factors on bioprocesses involving SSC $[7,8]$. Many of the fungal biocontrol agents are applied in the field in the form of conidia (asexual spores of the fungi) because of their small size and their ability to be massively produced in a dormant stage [9]. One essential variable for the conidiogenesis is the aeration rate and in SSC systems, a possible way to induce and extend conidiogenesis, leading to high sporulation indexes, is through the application of a water stress [10]. Applied at the moment of maximum biomass production, water stress results from stopping progressively the wet air influx-needed for mycelial development-and to replace it by dry air with an increased aeration rate. As a consequence, the medium is progressively dried and this detrimental change will be perceived by the fungus as a nutritional stress (indeed, fungal nutrition is carried out through absorbotrophy, which requires the presence of an aqueous film surrounding the fungal cells to occur). As a physiological response, the fungus thus stops its vegetative growth and initiates its asexual reproduction, forming conidia [7]. Besides, the evaporation of excess water releases free spaces in the medium, increasing the overall sporulation index. Water stress thus works as an inducer of conidiogenesis, and when carried out progressively, the drying of the medium can extend conidia production for several days, as long as the minimal fungal metabolic requirements are fulfilled [2]. Not all SSC processes involving the growth of a fungus lead to increased conidia production when operated under water stress; however, the conidia obtained in this way exhibit an increased viability for a longer period as low hydration is necessary for the conidia to stay dormant. This process also prevents potential undesirable microorganisms from contaminating the medium [11].

So far, several SSC bioreactors have been designed for the production of fungal metabolites and biomass [10-14]. However, the use of traditional SSC bioreactors is complicated due to the need to sterilize the bioreactor between successive cultures, the fact that it consists of several parts that must be assembled and the high cost due to the necessity to use stainless steel. Therefore, there is a need for easyto-use, efficient, and less cumbersome reactors. Accordingly, the present study aims to present a new design of a large disposable SSC bioreactor (DSSCB) belonging to the packed-bed category, which can efficiently process $6 \mathrm{~kg}$ of substrate (on a dry weight basis), which is ergonomic and space-saving due to its small size and weight $(641 \mathrm{~g})$. The particular metabolic activity that was chosen for this demonstration is the production of conidia from the biocontrol agent Trichoderma asperellum, cultivated on a mixture of agro-industrial byproducts undergoing water stress at the end of the vegetative growth. 


\section{Materials and Methods}

\section{Configuration of the Disposable Solid-State Culture Bioreactor (DSSCB)}

The critical restrictions behind the present innovation were:

- the bioreactor must be efficient to produce biological control agents like conidia at a scale superior to $5 \mathrm{~kg}$ dry substrate (DS),

- the bioreactor must be inexpensive and ergonomic (easy-to-use to carry out SSC in a laboratory with basic equipment and easy to handle to safely bring fermented material in remote agricultural areas),

- the bioreactor should allow the safe storage and conservation of fermented material (no downstream transfers of material should be needed before the use of the material at the application location).

Due to these constraints, the DSSCB is specifically designed to produce biomass and metabolites of biological origin. It is compact and made of a flexible plastic (polyethylene terephthalate) that can be easily sterilized (when it is necessary to operate in asepsis). The bioreactor is a bag with two main compartments. Its characteristics are summarized in Fig. 1, where the numbers indicate the different components. The first compartment is the base (10 in Fig. 1), which serves as an aeration system (and which can be used to apply water stress by blowing dry air through the bed) and a support for the bioreactor. The second compartment is the fermentation chamber (20 in Fig. 1), which has a working volume of $39.52 \mathrm{~L}(\mathrm{~L} \times \mathrm{W} \times \mathrm{H}: 0.52 \times 0.40 \times 0.19 \mathrm{~m})$. These two compartments (the base and the fermentation chamber) are made of the same flexible plastic. To allow aeration during the culture, the base has an inlet orifice (12 in Fig. 1) that can be connected to a source of gas, like dry or wet air. This inlet is connected to the central aeration channels (11 in Fig. 1). The distribution of the air to the fermentation chamber occurs through three cylindrical aeration channels in the base; these channels are parallel to one another and are perforated on the top, where they connect with the fermentation chamber (110 in Fig. 1). These aeration channels also communicate with each other through orifices (111 in Fig. 1). This configuration allows uniform distribution of air to the fermentation chamber.

The two compartments are separated by a micro-perforated grid (30 in Fig. 1) that is fixed to the base, being located on top of the aeration channels, between the aeration holes and the fermentation chamber. It has several functions: it supports the solid substrate and improves aeration of the fermentation chamber by preventing solid particles from clogging the aeration holes. It is also used
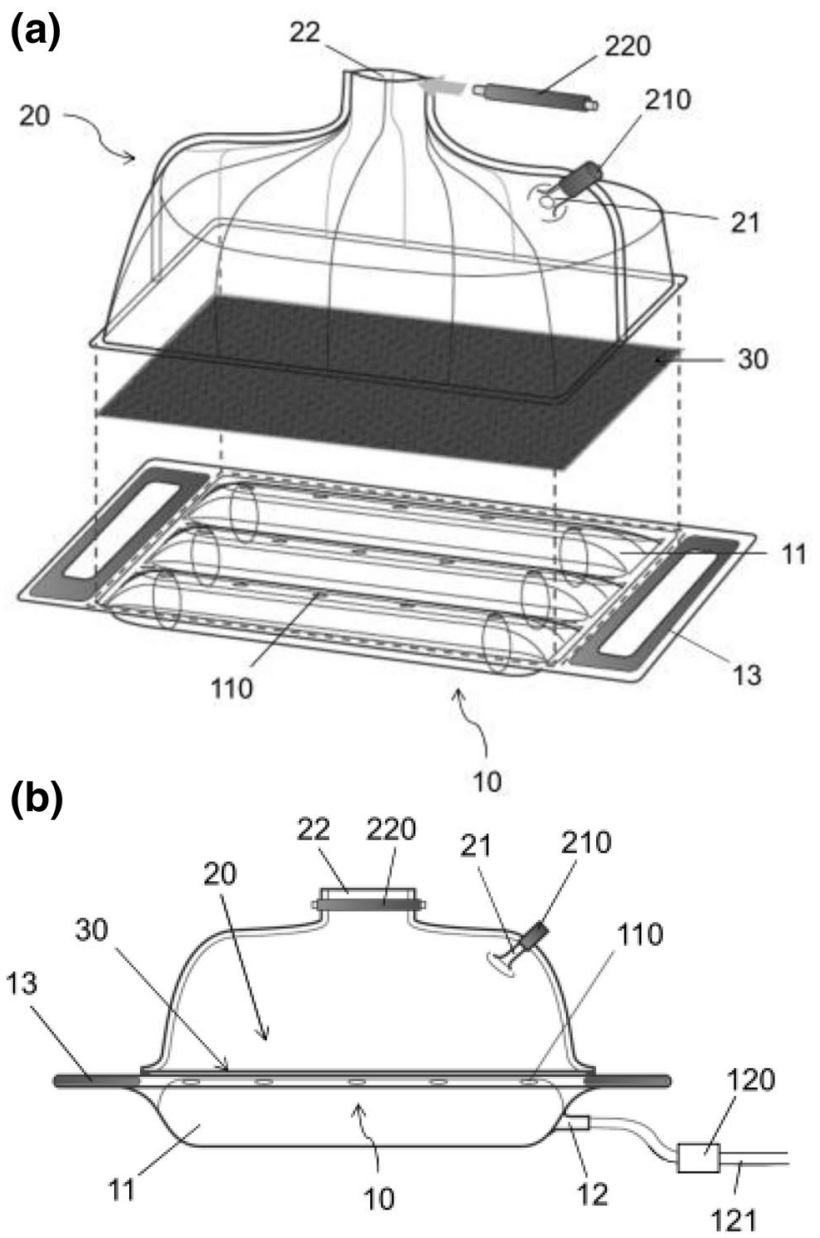

(c)

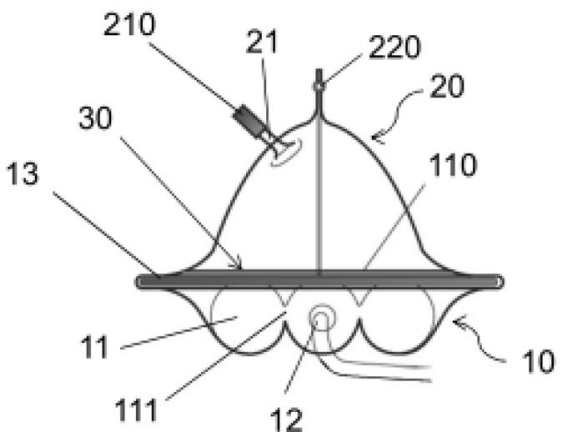

Fig. 1 Schematic representation of the bioreactor a Exploded perspective view. b Front view. c Side view. 0: basal portion; 11: aeration channel; 12: inlet orifice; 13: handles; 20: fermentation chamber; 21: outlet orifice; 22: opening; 30: micro-perforated grid; 110: aeration hole; 111:communication orifice; 120: air filter; 121: supply duct; 210: air filter; 220: removable fastening device

as a filter, especially when one wants to recover compounds contained in the fermenting material by leaching them with a liquid. This liquid passes through the aeration holes, from the fermentation chamber into the base. It is made of semi-rigid polyethylene terephthalate and thereby reinforces the base. Its meshes are of the order of $200 \mu \mathrm{m}$. 
The base has handles (13 in Fig. 1) to facilitate the manipulation of the bioreactor. The fermentation chamber has an opening at the top (22 in Fig. 1) that is used for introducing and removing solid material. This opening is equipped with a removable fastening device (220 in Fig. 1). The bioreactor is also equipped with removable air filters $(120,210$ in Fig. 1) located at the inlet hole of the base and at the outlet orifice (21 in Fig. 1) of the fermentation chamber. In addition, the recirculation of liquid from the base to the fermentation chamber is made possible by connecting the inlet orifice of the base with the outlet orifice of the fermentation chamber. Finally, the bioreactor cost is $30 €$.

\section{Operation and Recovery of Fermented Substrates from the DSSCB}

\section{Operation Process}

The operation of the DSSCB consists of the following steps:

- Solid, dry, or previously moistened substrate (impregnated with a culture medium suitable for the growth of the microorganism) is placed in the fermentation chamber (20) on the micro-perforated grid (30).

- The loaded bioreactor is then sterilized, for example, by autoclaving or ionization. This step can be omitted if the process does not require sterile conditions.

- To start the culture, a liquid suspension of the microorganism is introduced via the opening to inoculate the medium. To ensure uniform distribution of this inoculum, the whole is mixed (i) using a sterile forceps introduced through the upper opening and (ii) by carrying out rotational movements after closing the bioreactor. It is also possible to mix the substrate and the liquid suspension in a sterile container before filling the DSSCB.

- During the culture phase, the solid medium is aerated through the ventilation system of the base, for example, by injecting air (dry or wet), via the inlet orifice (12) of the base, using the filter to maintain asepsis of the system, if necessary. The humidity of the inlet air can be controlled, enabling the application of a specific water stress to favor the fermentation process.

- Once the time set for fermentation has elapsed, the fermented substrate is dried by aerating with dry air-then it can be directly used or stored for some time in the bioreactor before use. It can also be transported within the bioreactor, if appropriate.

\section{Recovery of Fermented Products of Interest}

If the product of interest is the fermented solid substrate, it can be removed directly from the fermentation chamber through its large opening. It is also possible to recover the useful product in liquid form using the following steps:

- a liquid is introduced into the fermentation chamber through its large opening;

- the liquid is mixed with the fermented product inside the fermentation chamber;

- the enriched liquid of microorganisms and metabolites flows to the base;

- the enriched liquid is recovered through the hole of the base.

\section{Implementing a Fermentation with the DSSCB for the Production of Conidia}

\section{Fungal Strain}

Trichoderma asperellum $\mathrm{G} 3$ from the collection of "Biotechnologie Environmentale et Chimiometrie, IRD/IMBE (Marseille, France)" was used. The apical growth of the strain on potato dextrose agar (PDA) varied from 16 to $18 \mathrm{~mm} /$ day and its sporulation index on sugarcane bagasse supplemented with nutrient medium was $1.12 \times 10^{8}$ spores/g of dry substrate [16]. The conidia were stored in a $5 \mathrm{~mL}$ glass bottle at $4{ }^{\circ} \mathrm{C}$ on PDA.

\section{Implementing the SSC}

In order to determine the suitability of the DSSCB for the production of conidia, SSCs were conducted at laboratory scale in Erlenmeyer flasks (5 g DS) and at pilot-scale using the DSSCB (6 kg DS and a bed height of $15 \mathrm{~cm}$ ). A mixture of agro-industrial waste was used: grapevine shoots $(33.33 \%)$, sugarcane bagasse (10\%), wheat bran (33.33\%), olive pomace (13.33\%) and potato flakes (10\%). The solid substrate was moistened at $50 \%$ (wet basis) with distilled water and sterilized at $121^{\circ} \mathrm{C}$ for $2 \mathrm{~h}$. The fungal conidia were produced using Erlenmeyer flasks with PDA. Then, the suspension of conidia was prepared using distilled water and mixed into the sterilized solid substrate to give an inoculation density of $2 \times 10^{7}$ conidia/g DS and a moisture content of $66 \%$ (wet basis). These culture conditions are adapted from the ones used by Hamrouni et al. [17] for the production of secondary metabolites, conidia, and enzymes using the same strain. The inoculated medium was subsequently transferred into the bioreactors before being incubated for one week at $25{ }^{\circ} \mathrm{C}$. A zero time sample was collected just before incubation and stored at $-20^{\circ} \mathrm{C}$ for analysis. SSCs were carried out in flasks without forced aeration while the DSSCB fermentation was carried out under forced aeration conditions using air at the rate of 10 to $45 \mathrm{~L} / \mathrm{min}\left(1 \mathrm{~atm}\right.$ and $\left.25^{\circ} \mathrm{C}\right)$. From the beginning of the process until $23 \mathrm{~h}$, water-saturated air (made possible by passing the air through a humidifier) was used at the rate of $10 \mathrm{~L} / \mathrm{min}$ to initiate the germination of the 
conidia. After $23 \mathrm{~h}$, the humidifier was disconnected and dry air was used to aerate the bioreactor. From 23 to $47 \mathrm{~h}$, the aeration rate was gradually increased to $45 \mathrm{~L} / \mathrm{min}$ to apply a progressive water stress. Then, after $50 \mathrm{~h}$, the aeration rate was progressively reduced to $25 \mathrm{~L} / \mathrm{min}$. During the process, the mass of the fermenting substrate inside the DSSCB was monitored using an electronic platform balance (KERN \& SONS GmbH, Germany) and the temperature was measured using a meat thermometer (OWIM GmbH, Germany) in the core of the bed at $7.5 \mathrm{~cm}$ depth. Samples were collected from the entire flask and the fermentation medium of the DSSCB through core sampling on all of the bioreactor bed section at five points (the center corresponding to a first sample and the four angles subsequently mixed together, corresponding to a second sample). The sampling was performed over time to evaluate moisture content, $\mathrm{pH}$, and content of conidia. Laboratory scale experiments were carried out in duplicate.

\section{Microscopic Observations of the Fermentation Medium in the DSSCB}

Samples were dyed with cotton blue (callose-specific dye) and observed under a microscope in order to follow the development of the fungus (germination of conidia, growth of the mycelium and conidiogenesis) and to confirm that the substrate was not contaminated by any other microorganism. A conidium is considered germinated when the germinated tube is equal to or greater than the diameter of the conidium.

\section{$\mathrm{pH}$ and Moisture Content Assessment}

One gram of fermented substrate was added to $25 \mathrm{~mL}$ of distilled water and triturated using an Ultra Turrax homogenizer (IKA, China). The $\mathrm{pH}$ of the suspension was then determined using a $\mathrm{pH}$ meter (HANNA, Italy).

Moisture contents (on a wet basis) were determined after drying for $24 \mathrm{~h}$ at $105^{\circ} \mathrm{C}$.

\section{Conidia Content}

The conidia content was evaluated by mixing $1 \mathrm{~g}$ of sample and $50 \mathrm{~mL}$ of distilled water containing Tween $80(0.01 \%)$. Then, $1 \mathrm{~mL}$ was diluted appropriately and the conidia counted using a Mallassez cell.

\section{Results and Discussion}

\section{Evolution of Trichoderma Grown on a Mixture of Agro-Industrial Waste in the DSSCB}

The conidia germinated after $20 \mathrm{~h}$ and began to elongate to form the mycelium. After $23 \mathrm{~h}$, all of the conidia had
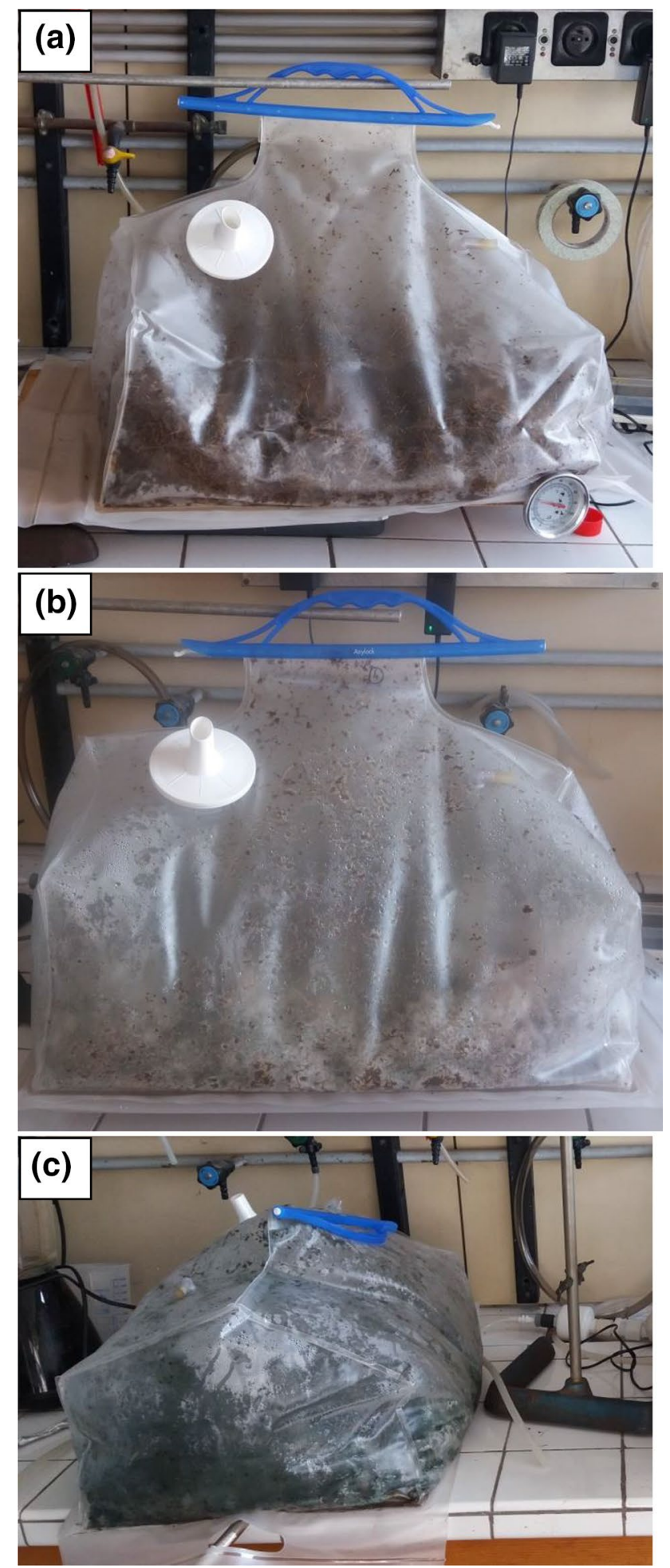

Fig. 2 Macroscopic view of the DSSCB showing the changes in color and the aspect of the fermenting substrate $(\mathbf{a}-\mathbf{c})$

germinated, marking the end of the germination phase. Conidiogenesis began after $48 \mathrm{~h}$. This evolution was marked by notable macroscopic changes of the fermenting substrate, 
including the gradual appearance of a white mycelium and then green conidia (Fig. 2a-c).

\section{Evolution of Physical Parameters}

At the laboratory scale, the variation of the physical parameters was negligible and no significant change was observed for the $\mathrm{pH}$, temperature and moisture content (data not shown). However, at the pilot scale, the evolution of the core temperature, $\mathrm{pH}$, moisture content, and overall bed weight changed during the SSC (Fig. 3). The process started at $25{ }^{\circ} \mathrm{C}$ with a low aeration rate of $10 \mathrm{~L} / \mathrm{min}$ during $23 \mathrm{~h}$ to initiate the germination of conidia and vegetative growth. This vegetative growth generated an increase of temperature of which the peak reached $48{ }^{\circ} \mathrm{C}$ after $44 \mathrm{~h}$ of process. Afterward, the temperature decreased as the aeration rate increased to $45 \mathrm{~L} / \mathrm{min}$ after $47 \mathrm{~h}$, suggesting a possible efficient heat removal through water evaporation as the water stress is implemented. This decreased temperature could also be the consequence of a reduced metabolic activity following the temperature increase. This hypothesis could be confirmed with a monitoring of the metabolic activity through, for example, oxygen uptake rate measurement. The temperature notably reached a minimum value of $22{ }^{\circ} \mathrm{C}$ after $68 \mathrm{~h}$, before increasing again until $31{ }^{\circ} \mathrm{C}(140 \mathrm{~h})$ as the aeration rate is progressively reduced to $25 \mathrm{~L} / \mathrm{min}$ (starting from $50 \mathrm{~h}$ ). The moisture content and overall bed weight decreased, particularly after $50 \mathrm{~h}$ of process passing from 66 to $34 \%$ and 18 to $9.7 \mathrm{~kg}$ - respectively — at the end of the process. Regarding the $\mathrm{pH}$, there was only a slight increase from 6.4 to 7.0.

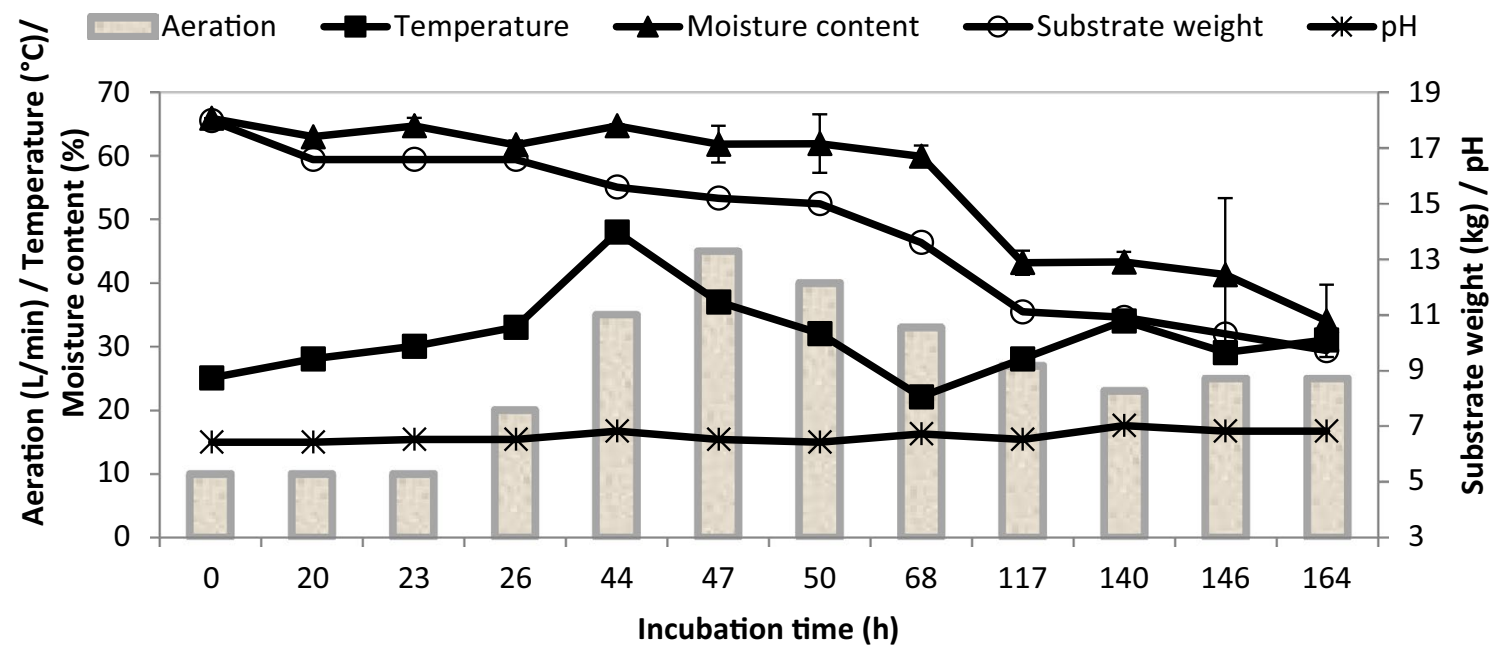

Fig. 3 Evolution of physical parameters in the DSSCB

Fig. 4 Profiles of conidia produced by Trichoderma asperellum grown on a mixture of agro-industrial waste in flask and in the DSSCB

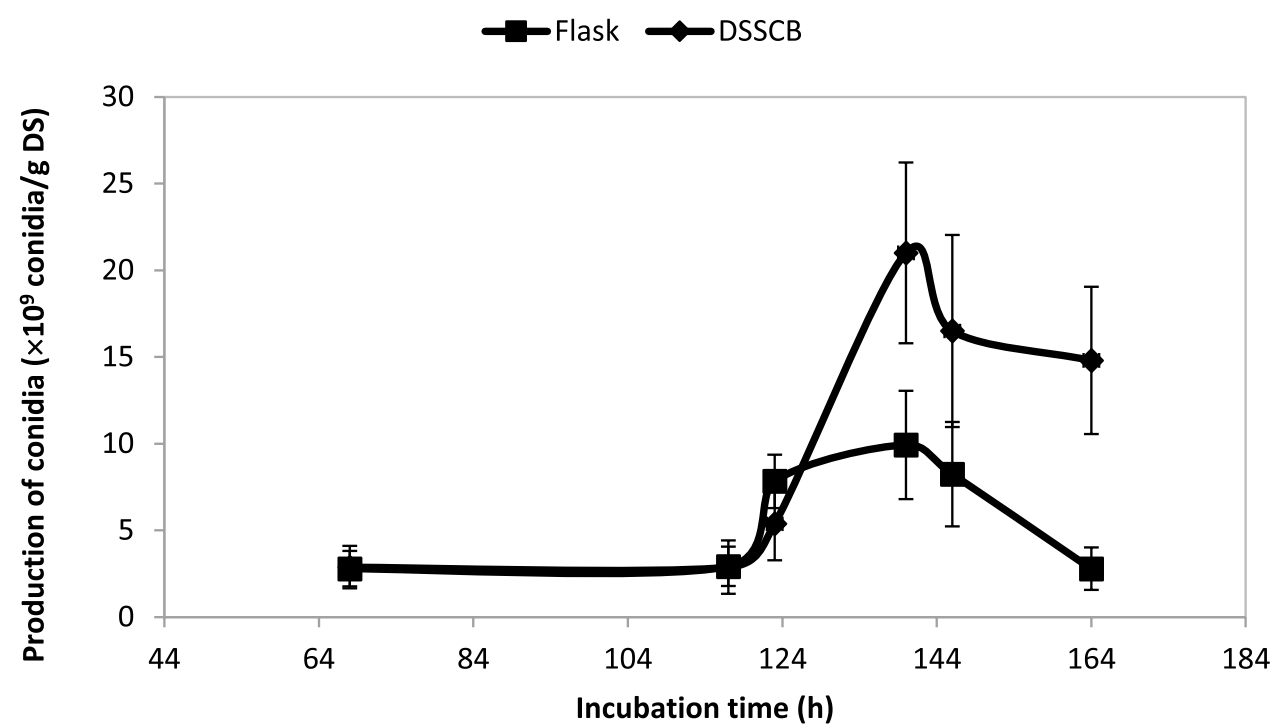




\section{Production of Conidia}

At both scales, the conidia production followed a similar tendency as the conidia indexes remained constant until $117 \mathrm{~h}$ before increasing (Fig. 4).

The conidia production started at the same moment in the DSSCB as well as the flasks and the maximum contents were obtained after $140 \mathrm{~h}$ of fermentation. The highest conidia content was obtained using the DSSCB $\left(2.10 \times 10^{10} \pm 5.21 \times 10^{9}\right.$ versus $9.92 \times 10^{9} \pm 3.12 \times 10^{8}$ conidia/g DS for the flasks). The forced aeration and the water stress characterized by the reduction of the moisture content could have enhanced the production of conidia in the DSSCB. This difference in conidia contents is consistent with reported results that demonstrated a positive effect of aeration on T. asperellum conidia production [18]. It is thus most likely that the positive effect of aeration on conidiogenesis overcame the detrimental effect of the temperature rise at the larger scale.

Using the same strain of $T$. asperellum, Hamrouni et al. [19] obtained conidia production of $8.55 \times 10^{9} \pm 4.00 \times 10^{6}$ conidia/g DS, in a packed-bed bag bioreactor containing $9 \mathrm{~kg}$ of moist medium. In comparison, our production yield is almost 2.5 times higher. However, it is worth mentioning that the conditions they used were optimized for both 6-pentyl-a-pyrone and conidia production, that their medium contained Jatropha cake and olive oil in addition to the mixture we used, and that they observed a moisture content decrease of only $10 \%$ in their bioreactor. Considering the total initial quantity of dry medium processed in the DSSCB, the overall conidia/bioreactor value is $1.26 \times 10^{14}$. A single bioreactor would allow to treat almost $10^{6}$ plants (with a treatment application of $10^{8}$ conidia per plant [20]).

\section{Comparison of the DSSCB with Existing Bioreactors}

One of the disadvantages of SSC is related to the difficulty in removing the metabolic heat generated during the culture, which is directly linked to the growth rate of the microorganism. This situation can lead to high temperatures that are detrimental to the process organism, particularly at higher scales of production. The various types of bioreactor designs have different efficiencies with respect to heat removal; Mitchell et al. [21] distinguish four classes of batch-operated bioreactors, depending on whether they have forced aeration or not and are agitated or not. Typically, in a tray bioreactor-static and without forced aeration-the bed height is a critical factor to avoid the formation of detrimental temperature gradients [22]. Using such a bioreactor, Jou and Lo showed that the height of the bed should not exceed $1 \mathrm{~cm}$ to get an optimal growth rate for a Trichoderma sp. strain [23]. Such conformation needs large production surfaces which are not suited to our restrictions.
The DSSCB falls in the static packed-bed bioreactor category, which is characterized by the presence of forced aeration that aids in the replenishment of oxygen and mitigates accumulation of heat and carbon dioxide. It usually consists of an enclosed cylindrical glass or metal tube or drum in which the substrate is inoculated. These bioreactors are reusable and require the transfer of the fermented material at the end of the process, a step during which the operator may be in contact with the biological material or that may contaminate the surrounding lab. In addition, each reuse necessitates a preliminary meticulous cleaning of the bioreactors. Moreover, pilot-scale SSCs often require separate sterilization of the solid medium and the bioreactor before the inoculated medium is aseptically introduced in the sterile bioreactor [24]. The DSSCB bypasses these time-consuming steps as the medium can be autoclaved directly inside the device. Besides, it protects the user from exposure, as the bioreactor does not have to be emptied and can be stored directly (after the fermented material has been properly dried in situ by aerating the bed with dry air).

The temperature rise in packed-bed bioreactors is unavoidable for an aerobic process carried out on more than $5 \mathrm{~kg}$ DS. Various strategies of heat removal exist including the use of complex cooling devices-such as cooling plates or agitation systems involving mechanical blades or rotating drum-type apparatus. These cooling devices were not considered in the case of the DSSCB. Indeed, they would not be disposable and would therefore add duration to the already time-consuming pre- and post-fermentation steps (more elements to clean). For this reason, heat dissipation in the DSSCB mainly relies on the forced air aeration. Therefore, microorganisms able to tolerate a rise of temperature (when this occurs) without negatively impacting the final yields would be preferable for this bioreactor.

Several studies have reported the production of conidia using bag-type bioreactors. For example, De la Cruz-Quiroz et al. [25] obtained a maximum sporulation index of $1.2 \times 10^{9}$ conidia/g DS using T. asperellum grown on corn cob in a bioreactor consisting of a polyethylene bag, operated without forced aeration. Although this index is high, it is lower than the one we obtained $\left(2.1 \times 10^{10}\right.$ conidia/g DS $)$ probably because of the influence of aeration. In addition, the scales are different as they carried out the SSC on only $15 \mathrm{~g}$ of solid medium [25] compared to $6 \mathrm{~kg}$ DS used in our study. The results obtained with the DSSCB are therefore encouraging.

\section{Limitations and Perspectives of the DSSCB}

The configuration of the DSSCB seems suitable for the production of conidia by T. asperellum grown under water stress as we obtained a good overall conidia index. However, this high yield is accompanied by an important temperature rise 
that may be detrimental to the production of some compounds. Indeed, the synthesis of some secondary metabolites is very sensitive to temperature variations [26]. Following this idea, producing high quantities of secondary metabolites through aerobic processes with the DSSCB could generate lasting temperature gradients that may inactivate the biomass. This temperature increase, due to the fungal metabolism, is also the consequence of the compaction of the substrate that causes air channeling across the bed and subsequent heat and mass heterogeneities [15]. A way to partially reduce the compaction effect is by introducing a solid material acting as an inert support in the medium, providing desirable physical properties like porosity to the bioreactor bed [27]. However, the most efficient way to prevent the appearance of mass and energy gradients is through the application of agitation specifically adapted to the fungus in such a way as not to disrupt its structures. Hence, one of the major limits of this bioreactor is the absence of a proper system of agitation, although the bioreactor is light enough $(18 \mathrm{~kg})$ to allow the use of a simple intermittent agitation system (with a swinging shelf or even performed manually). In any case, additional experiments are necessary to evaluate the performance of the bioreactor for the production of various compounds including enzymes, conidia, and secondary metabolites, using different microorganisms.

\section{Conclusion}

The DSSCB is a new bioreactor design that allows the fermentation of up to $18 \mathrm{~kg}$ of solid substrate (wet weight basis) under forced air conditions for the production of conidia $\left(2.10 \times 10^{10} \pm 5.21 \times 10^{9}\right)$ of T. asperellum, a fungal strain used in biocontrol. This result is higher than the one obtained using flasks at the laboratory scale $\left(9.92 \times 10^{9} \pm 3.12 \times 10^{8}\right.$ conidia/g DS). Taking into account the quantity of solid substrate used for the test, up to $1.26 \times 10^{14}$ conidia are estimated to have been generated. Based on the configuration of the bioreactor, these conidia can be carried easily and used in either a solid or a liquid formulation for biocontrol in crops. This is a significant advance in the field of metabolite production in solid-state culture as problems associated with the sterilization of the bioreactor prior to its reuse are avoided. To validate the developed bioreactor, it is necessary to test its suitability with other strains and for the production of secondary metabolites.

Acknowledgement The authors would like to thank IRD for providing the funds and the "Institut Méditerranéen de Biodiversité et d'Ecologie Marine et Continentale (IMBE)" of "Aix Marseille Université" for the support and technical facilities.

Authors Contribution QC and MST carried out the initial work on the DSSCB. YM and RH carried out the experiments. YM led the writing of the manuscript with support from all authors. BMY participated in the initial work on the DSSCB. SR initiated and supervised this research

Funding This work was supported by IRD.

Data Availability The data and bioreactor are available.

\section{Compliance with Ethical Standards}

Conflict of interest The authors declare that there are no conflicts of interest.

\section{References}

1. Pandey, A.: Solid-state fermentation. Biochem. Eng. J. 13, 81-84 (2003). https://doi.org/10.1016/S1369-703X(02)00121-3

2. De la Cruz Quiroz, R., Roussos, S., Hernández, D., Rodríguez, R., Castillo, F., Aguilar, C.N.: Challenges and opportunities of the bio-pesticides production by solid-state fermentation: filamentous fungi as a model. Crit. Rev. Biotechnol. 35, 326-333 (2015). https ://doi.org/10.3109/07388551.2013.857292

3. Roussos, S., Lonsane, B.K., Raimbault, M., Viniegra-Gonzalez, G.: Advances In Solid State Fermentation. Springer, Dordrecht (1997)

4. Thomas, L., Larroche, C., Pandey, A.: Current developments in solid-state fermentation. Biochem. Eng. J. 81, 146-161 (2013). https://doi.org/10.1016/j.bej.2013.10.013

5. Ministère de la Transition écologique et solidaire: Plan Ecophyto II+. https://www.consultation-ecophyto2plus.gouv.fr/ (2020) Accessed 15 July 2020

6. Lehmann, E.R.G.: Impact Assessment of Pesticides Applied in Vegetable-Producing Areas in the Saharan Zone the Case of Burkina Faso (2017)

7. Hassouni, H.: Physiologie de la sporulation des champignons ilamenteux pour la production de spores et d'enzymes en fermentation en milieu solide. Thèse. $\mathrm{N}^{\circ}$ d'ordre: TPA/2/2007. Institut Agronomique et Vétérinaire Hassan II. Maroc (2007)

8. Pandey, A., Soccol, C.R., Larroche, C.: Current Developments in Solid-State Fermentation. Springer, New York (2008)

9. Coninck, E., Scauflaire, J., Gollier, M., Liénard, C., Foucart, G., Manssens, G., Munaut, F., Legrève, A.: Trichoderma atroviride as a promising biocontrol agent in seed coating for reducing Fusarium damping-off on maize. J. Appl. Microbiol. (2020). https://doi. org/10.1111/jam.14641

10. Santa, H.S.D., Santa, O.R.D., Brand, D., de Vandenberghe, L.P.S., Soccol, C.R.: Spore production of Beauveria bassiana from agroindustrial residues. Braz. Arch. Biol. Technol. 48, 51-60 (2005). https://doi.org/10.1590/S1516-89132005000400007

11. De la Cruz, Q.R., Roussos, S., Tranier, M.S., Rodriguez, R., Ramírez Guzmán, K.N., Aguilar, C.N.: Fungal spores production by solid-state fermentation under hydric stress condition. J. Bioprocess Chem. Technol. 11, 1-6 (2019)

12. Roussos, S., Raimbault, M., Prebois, J.-P., Lonsane, B.K.: Zymotis, a large scale solid state fermenter design and evaluation. Appl. Biochem. Biotechnol. 42, 37-52 (1993). https://doi.org/10.1007/ BF02788900

13. Ruiz, H.A., Rodríguez-Jasso, R.M., Rodríguez, R., ContrerasEsquivel, J.C., Aguilar, C.N.: Pectinase production from lemon peel pomace as support and carbon source in solid-state fermentation column-tray bioreactor. Biochem. Eng. J. 65, 90-95 (2012). https://doi.org/10.1016/j.bej.2012.03.007 
14. Rodríguez-Jasso, R.M., Mussatto, S.I., Sepúlveda, L., Agrasar, A.T., Pastrana, L., Aguilar, C.N., Teixeira, J.A.: Fungal fucoidanase production by solid-state fermentation in a rotating drum bioreactor using algal biomass as substrate. Food Bioprod. Process. 91, 587-594 (2013). https://doi.org/10.1016/j.fbp.2013.02.004

15. Pitol, L.O., Biz, A., Mallmann, E., Krieger, N., Mitchell, D.A.: Production of pectinases by solid-state fermentation in a pilotscale packed-bed bioreactor. Chem. Eng. J. 283, 1009-1018 (2016). https://doi.org/10.1016/j.cej.2015.08.046

16. Hamrouni, R., Molinet, J., Miché, L., Carboué, Q., Dupuy, N., Masmoudi, A., Roussos, S.: Production of coconut aroma in solidstate cultivation: screening and identification of Trichoderma strains for 6-pentyl-alpha-pyrone and conidia production. J. Chem. 2019, 1-7 (2019). https://doi.org/10.1155/2019/8562384

17. Hamrouni, R., Claeys-Bruno, M., Molinet, J., Masmoudi, A., Roussos, S., Dupuy, N.: Challenges of enzymes, conidia and 6-pentyl-alpha-pyrone production from solid-state-fermentation of agroindustrial wastes using experimental design and T. asperellum strains. Waste Biomass Valori. (2019). https://doi.org/10.1007/ s12649-019-00908-2

18. Hamrouni, R., Molinet, J., Dupuy, N., Taieb, N., Carboue, Q., Masmoudi, A., Roussos, S.: The effect of aeration for 6-pentylalpha-pyrone, conidia and lytic enzymes production by Trichoderma asperellum strains grown in solid-state fermentation. Waste Biomass Valori. (2019). https://doi.org/10.1007/s12649-01900809-4

19. Hamrouni, R., Josiane, M., Gregoria, M., Yiannis, K., Nathalie, D., Ahmed, M., Sevastianos, R.: From flasks to single used bioreactor: scale-up of solid state fermentation process for metabolites and conidia production by Trichoderma asperellum. J. Environ. Manage. 252, 109496 (2019). https://doi.org/10.1016/j.jenvm an.2019.109496

20. Barroso, F.M., Muniz, P.H.P.C., Milan, M.D., dos Santos, W.S., de Ferreira, N.C.F., Rodrigues, F., Carvalho, D.D.C.: Growth promotion of parsley (Petroselinum crispum L.) using commercial strains of Trichoderma spp. J. Agric. Sci. 11, 493 (2019). https:// doi.org/10.5539/jas.v11n4p493
21. Mitchell, D.A., Krieger, N., Berovič, M.: Solid-state fermentation bioreactors fundamentals of design and operation. In: Mitchell, D.A., Krieger, N., Berovič, M. (eds.) Solid-State-Fermentation Bioreactors, pp. 1-12. Springer, Berlin (2006)

22. Mitchell, D.A., Krieger, N., Stuart, D.M., Pandey, A.: New developments in solid-state fermentation. Process Biochem. 35, 12111225 (2000). https://doi.org/10.1016/S0032-9592(00)00157-6

23. Jou, R.-Y., Lo, C.-T.: Heat and mass transfer measurements for tray-fermented fungal products. Int. J. Thermophys. 32, 523-536 (2011). https://doi.org/10.1007/s10765-011-0934-x

24. Bandelier, S., Renaud, R., Durand, A.: Production of gibberellic acid by fed-batch solid state fermentation in an aseptic pilotscale reactor. Process Biochem. 32, 141-145 (1997). https://doi. org/10.1016/S0032-9592(96)00063-5

25. De la Cruz-Quiroz, R.D., Roussos, S., Hernandez-Castillo, D., Rodríguez-Herrera, R., López-López, L.I., Castillo, F., Aguilar, C.N.: Solid-state fermentation in a bag bioreactor effect of corn cob mixed with phytopathogen biomass on spore and cellulase production by Trichoderma asperellum. In: Jozala, A.F. (ed.) Fermentation Processes, pp. 43-56. Intechopen, London (2017)

26. Lind, A.L., Smith, T.D., Saterlee, T., Calvo, A.M., Rokas, A.: Regulation of secondary metabolism by the velvet complex is temperature-responsive in Aspergillus. G3 Genes Genomes Genet 6(12), 4023-4033 (2016). https://doi.org/10.1534/g3.116.033084

27. Carboué, Q., Claeys-Bruno, M., Bombarda, I., Sergent, M., Jolain, J., Roussos, S.: Experimental design and solid state fermentation: a holistic approach to improve cultural medium for the production of fungal secondary metabolites. Chemom. Intell. Lab. Syst. 176, 101-107 (2018). https://doi.org/10.1016/j.chemolab.2018.03.011

Publisher's Note Springer Nature remains neutral with regard to jurisdictional claims in published maps and institutional affiliations.

\section{Affiliations}

\section{Ynoussa Maïga ${ }^{1,2}$ (1) Quentin Carboué ${ }^{1} \cdot$ Rayhane Hamrouni $^{1,3} \cdot$ Marie-Stéphane Tranier $^{1} \cdot$ Yassine Ben Menadi $^{1,4}$. Sevastianos Roussos ${ }^{1}$}

1 Aix Marseille Univ, Avignon Université, CNRS, IRD, IMBE, Marseille, France

2 Université Joseph KI-ZERBO, Laboratoire de Microbiologie et de Biotechnologie Microbienne, 03 BP 7021 Ouagadougou, Burkina Faso
3 Univ. Manouba, ISBST, BVBGR-LR11ES31, Biotechpole Sidi Thabet, 2020 Ariana, Tunisia

4 BioIntrants Technologie, Zone Industrielle Bouteffeha, Beja, Tunisia 